\title{
Mapeamento topo-batimétrico de reservatório utilizando LIDAR e batimetria no Lago Paranoá - DF.
}

Amanda Cecília Neuhauss Aguiar ${ }^{1}$, Marco lanniruberto ${ }^{2}$, Welitom Rodrigues Borges ${ }^{3}$ and Henrique Llacer Roig ${ }^{4}$, Gabriela Nunes Turquetti ${ }^{5}$, Paulo Henrique Praça de França ${ }^{6}$

\section{Copyright 2019, SBGf - Sociedade Brasileira de Geofísica}

This paper was prepared for presentation during the $16^{\text {th }}$ International Congress of the Brazilian Geophysical Society held in Rio de Janeiro, Brazil, 19-22 August 2019.

Contents of this paper were reviewed by the Technical Committee of the $16^{\text {th }}$ International Congress of the Brazilian Geophysical Society and do not necessarily represent any position of the SBGf, its officers or members. Electronic reproduction or storage of any part of this paper for commercial purposes without the written consent of the Brazilian Geophysical Society is prohibited.

\section{Resumo}

Este estudo visa análisar a aplicação dos sistemas multibeam, single-beam e LIDAR a fim de gerar uma carta topobatimétrica 3D, determinar a curva Cota x Área x Volume do reservatório e analisar sua evolução ao longo dos anos, desde sua fundação, utilizando para isso dados de 1960 e 2009. A aquisição foi realizada utilizando um ecobatímetro mono-feixe ODOM Echotrac CVM de dupla frequência (33$200 \mathrm{kHz}$ ) e um ecobatímetro de alta resolução Teledyne Reason 7101. A carta topo-batimétrica foi gerada através da interpolação no software SURFER 13, utilizando o método krigging.

\section{Introdução}

Este trabalho teve como início de uma parceria entre a Universidade de Brasília (UnB) e a Agência Reguladora de Águas, Energia e Saneamento Básico do Distrito Federal (ADASA), com objetivo de calcular a atual capacidade volumétrica e área do Lago Paranoá e a partir destes dados, fazer análises a respeito da situação em que reservatório se encontra.

Reservatórios são formados, normalmente, pelo barramento de um curso d'água natural, com intuito de suprir algumas necessidades dos habitantes da cidade, como criar um estoque de água para garantir suplemento durante as estações secas, colaborar com a geração de energia elétrica e promover lazer aos habitantes.

Os reservatórios são conhecidos por terem, ao longo os anos, problemas relacionados com sedimentação. Por possuírem baixa energia hidráulica, atuam como uma bacia de captação e decantação de sedimentos transportados pelos afluentes. O reservatório forma uma espécie de armadilha, em que os grãos suspensos mais grossos formam deltas, caracterizados por uma frente sedimentar de progradação/assoreamento a jusante.

A taxa de sedimentação ou de assoreamento depende de fatores naturais, como a geologia, a geomorfologia, a pedologia, o clima e as mudanças do uso do solo nas proximidades da bacia (e.g.: Hosseini e Ashraf, 2015). Esta taxa em qualquer reservatório está relacionada também com fatores antrópicos, e a sua estimativa pode ser muito desafiadora (Walling, 1999).

É possível estimar a taxa de sedimentação de um lago a partir de três abordagens principais: processos de erosão do solo, transporte de sedimento e deposição. A primeira é uma função complexa a respeito da pedologia, geomorfologia, clima e uso do solo. A segunda depende de uma previsão de quantidade sedimentos ao longo das vias que ligam as áreas de produção e deposição, os quais dependem diretamente de uma medida do fluxo ao longo do curso d'água. A terceira e última pode ser estimada através de uma pesquisa topobatimétrica multi-temporal (Rowan et al., 1995;), e também através de outros métodos geofísicos, como a geoelétrica e a sísmica de reflexão.

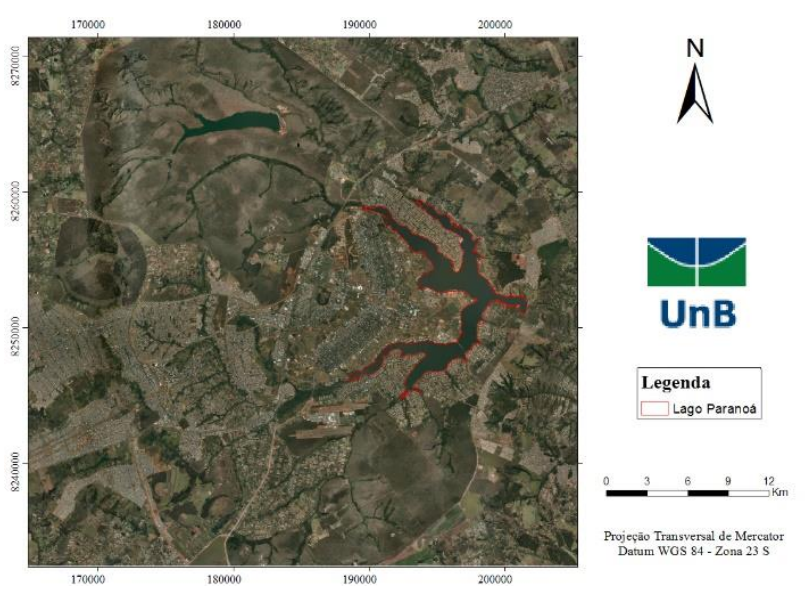

O Lago Paranoá, construído em 12 de setembro de 1959 através do represamento do rio Paranoá, foi idealizado antes de sua fundação como principal característica da paisagem de Brasília. A bacia do Lago Paranoá está integralmente localizada no Distrito Federal, sendo uma grande parte protegida por unidades de conservação, como as nascentes do Bananal e de Santa Maria (Torto). O Lago Paranoá é constituído, ao norte, pelas unidades hidrográficas do Bananal e Santa Maria, e ao sul, pela unidade hidrográfica do Riacho Fundo e Ribeirão do Gama (Dias, 2011). Todos esses afluentes das unidades deságuam no Lago Paranoá, e este possui apenas uma saída, localizada na represa que desemboca no Rio São Bartolomeu.

Dentro de um largo espectro de possibilidades para estimar a sedimentação e calcular o volume de um reservatório, a adoção de uma aquisição topo-batimétrica multi-temporal fornece uma evidência direta do volume e da geometria dos depósitos, método recomendado para monitoramento anual ou de longos períodos de tempo.

O uso da batimetria vem se firmando como ferramenta principal para geração de um modelo digital de fundo e o cálculo acurado do volume de reservatórios hídricos. Modelos digitais obtidos por meio de levantamentos com batimetria são de grande importância para a caracterização morfométrica de corpos hídricos e podem 
MAPEAMENTO TOPO-BATIMÉTRICO DO LAGO PARANOÁ - DF

auxiliar em estudos de evolução de assoreamento, qualidade da água, entre outros.

Mapeamentos utilizando aquisições de LIDAR (Light Detection and Ranging) vêm se desenvolvendo desde os anos 1990s (Grejner-Brzezinska et al. 2004). Este método é eficaz, com capacidade de capturar uma grande quantidade de dados com uma alta acurácia.

A batimetria, quando interpolada com dados de LIDAR pode fornecer um volume maior de informação a respeito do reservatório, podendo assim ser feito o cálculo da curva cota $x$ área $x$ volume com maior precisão e resolução. É necessário neste projeto uma perfeita integração entre os dados de topografia e de batimetria a fim de obter uma carta topo-batimétrica de alta confiabilidade.

Este trabalho possui como um dos objetivos auxiliar na compreensão de como ocorrem os processos de sedimentação e de retenção de sedimentos dentro do contexto de um reservatório localizado no Planalto Central, com características de uso do solo desordenado e com clima de Cerrado semi-árido. Outro objetivo seria contribuir com estudos de sistemas multi-temporais de topobatimetrias.

\section{Metodologia}

Nos ambientes submersos, a batimetria é um método rápido e eficaz de fazer leituras de profundidade. Esse método segue os princípios de propagação das ondas acústicas, ou seja, o tempo entre a emissão de feixes de ondas pelo transdutor e o retorno destas pelo receptor fornecem uma distância, e essas distâncias, quando reduzidos a um datum vertical em comum, fornecem valores de profundidade. Esse método possui dois tipos de sistemas: ecobatímetro monofeixe e o ecobatímetro multifeixe. O sistema monofeixe, emite um pulso acústico por vez, determinando uma cota de profundidade por ciclo. O sistema multifeixe emite simultaneamente uma grande quantidade de feixes, produzindo faixas de varredura que cobrem maior área.

Nos ambientes secos, o Perfilador é um método de medidas topográficas eficaz no qual o equipamento pode ser transportado por drone, helicóptero ou avião. Esse método faz o escaneamento do terreno através da emissão de feixes de laser no canal infravermelho próximo. O Perfilador separa o terreno de cobertura vegetal e de edificações a partir do retorno de cada pulso elétrico emitido em direção aos alvos, nesse sentido, tanto a linha do solo é mapeada como também tudo que se encontra acima dele é categorizado (vegetação, edificações, carros e outros elementos).

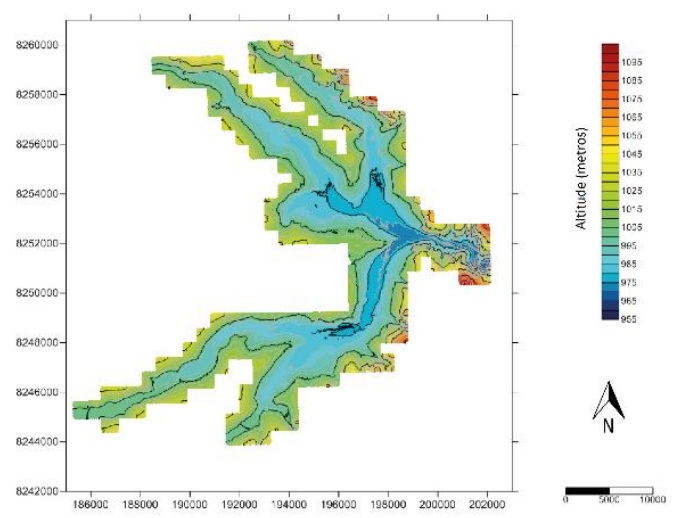

Figura 1: Carta topobatimétrica do Lago Paranoá gerada pelo software SURFER 13.

\begin{tabular}{ccc} 
COTA $(m)$ & AREA $\left(\mathrm{m}^{2}\right)$ & VOLUME $\left(\mathrm{m}^{3}\right)$ \\
955 & 0 & 0 \\
960 & 14.251 & 17.594 \\
965 & 80.213 & 217.379 \\
970 & 303.339 & 1.122 .194 \\
975 & 1.655 .307 & 4.681 .474 \\
980 & 6.741 .486 & 24.196 .056 \\
985 & 14.515 .359 & 76.899 .654 \\
990 & 21.606 .198 & 167.004 .022 \\
995 & 29.371 .812 & 294.220 .877 \\
1000 & 37.528 .552 & 460.792 .734 \\
\hline
\end{tabular}

Tabela 1: tabela de Cota x Área x Volume do /lago Paranoá.

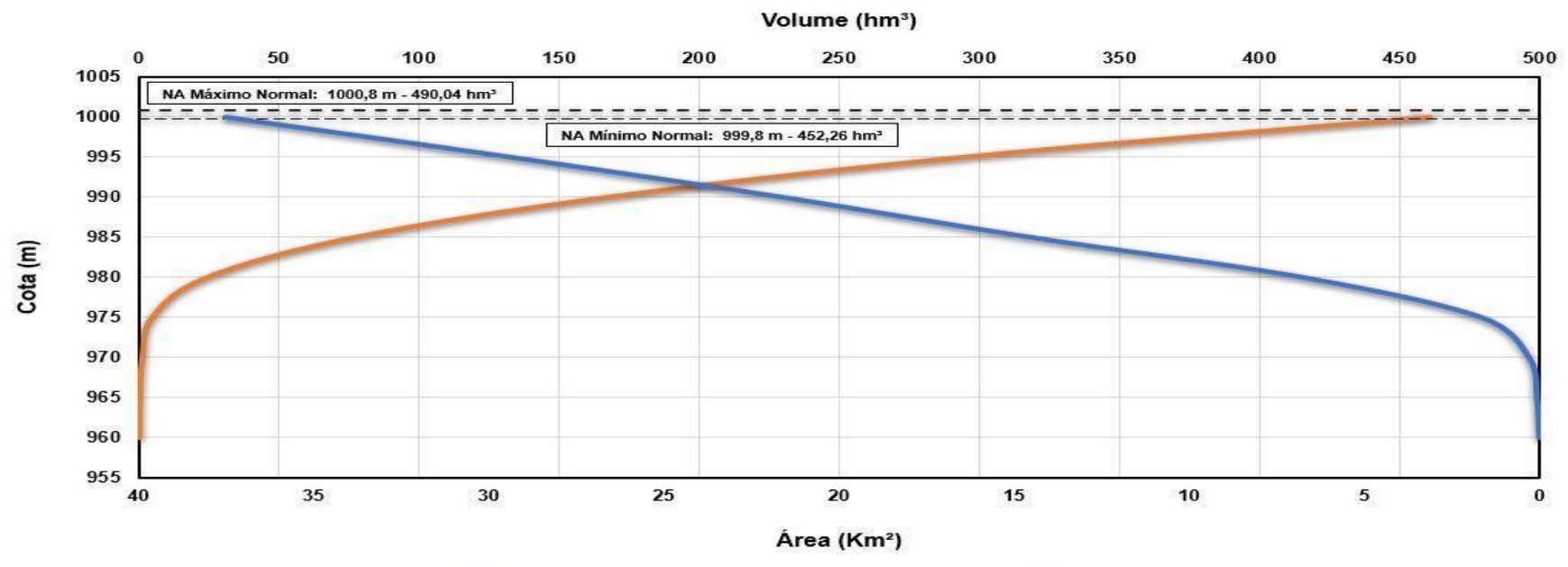

Gráfico 1: Curva Cota x Área x Volume do Lago Paranoá 


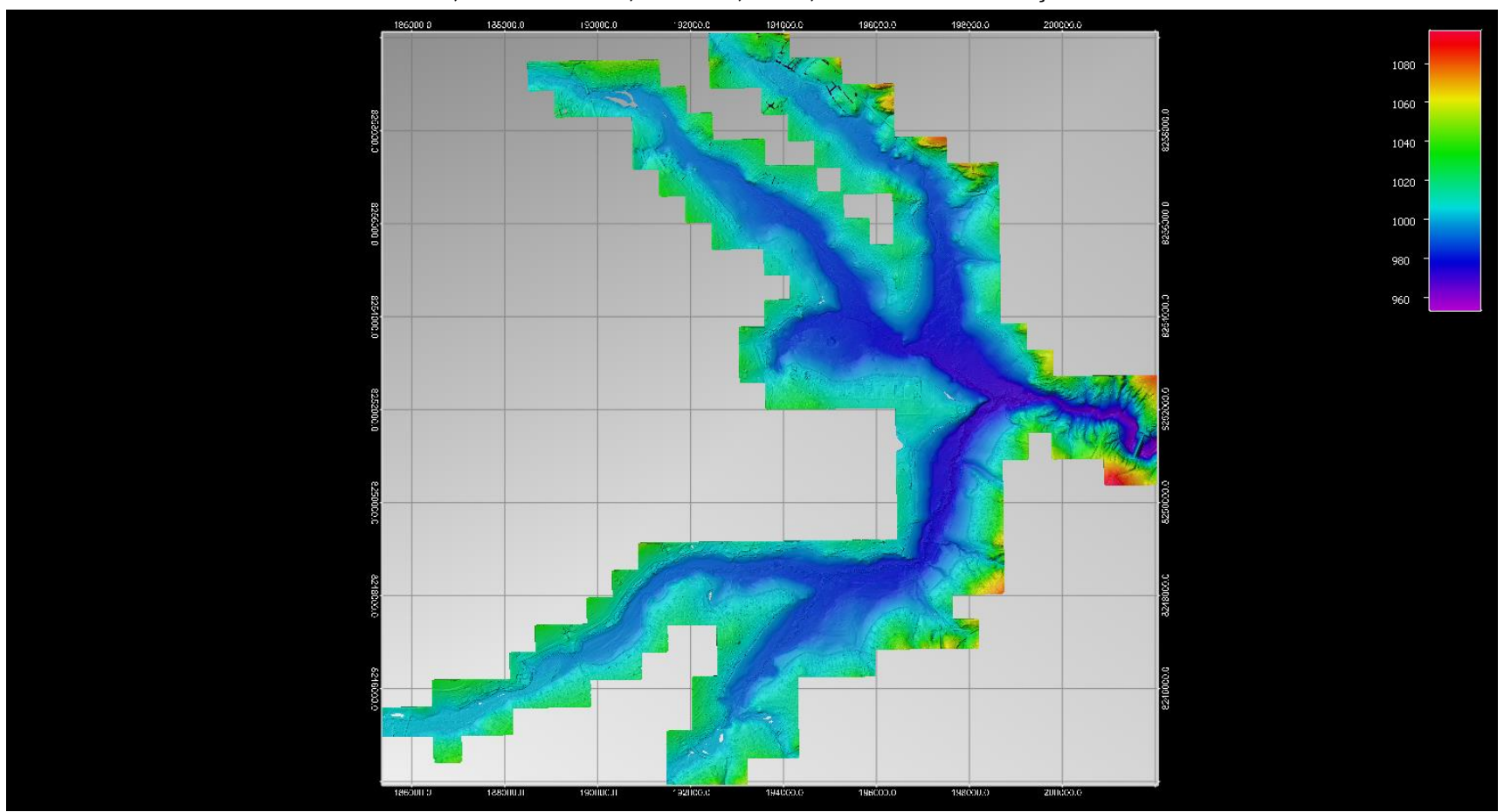

Figura 2: carta topo-batimétrica do Lago Paranoá gerado pelo software FLEDERMAUS.

A investigação batimétrica foi realizada em 5 campanhas em 2016 e 2017. A aquisição utilizando o Single-Beam foi feita com um ecobatímetro de dupla frequência (33$200 \mathrm{kHz}$ ) da ODOM Echotrac, modelo CVM. Para a navegação, foi utilizado o Software HYPACK 2010 e o sistema de posicionamento GNSS foi realizado pelo receptor Trimble DSM 232. A aquisição Multi-Beam foi executada utilizando o ecobatímetro Teledyne Reason 7101, o perfilador de som ODOM DIGIBAR Pro, e o MRU (sensor de movimento) SPAN-CPT da NovAtel, conectados a uma suíte de navegação PDS 2000.

O processamento dos dados batimétricos multi e monofeixe foram realizado em softwares distintos. Os dados de mono-feixe foram processados utilizando a suíte de navegação HYPACK, onde foi possível fazer a filtragem de pontos espúrios e redução dos dados para o datum do geóide. Os dados de Multi-Feixe foram processados no software CARIS, onde foi feita a análise de velocidade dos dados, a redução dos dados para o datum do geóide (Nível do Mar), o ajuste dos parâmetros de calibração e, por final, a filtragem dos dados espúrios.

O Perfilamento Laser foi executado por meio da tecnologia Light Detection And Ranging - LIDAR. O sensor utilizado foi o ALS-60, da Leica Geosystems, a unidade de medição inercial utilizada foi o IPAS20, modelo NUS5, também da Leica Geosystems, com receptor GNSS geodésico, de dupla frequência $L 1 / L 2$, acoplado. A aeronave utilizada para transportar os equipamentos foi o Azteca PA-23-250, da Piper Aircraft. Os dados do Perfilamento Laser foram adquiridos e processados pela empresa TOPOCART.

Após coletados e processados os dados de Batimetria e de LIDAR, estes foram integrados utilizando o software FLEDERMAUS, onde foi possível também fazer uma análise de qualidade dos dados.
A integração dos dados de batimetria e LIDAR gerou um mapa Topobatimétrico de resolução de $5 \mathrm{~m}^{2}$ da região. A interpolação resultou em um Modelo Digital de Elevação (MDE), este foi gerado através do software Surfer 13 através da ferramenta Grid Data, o método de interpolação escolhido foi o Krigging, interpolador estocástico que faz uso da teoria da probabilidade, e incorpora critérios estatísticos na determinação do peso atribuídos às amostras no processo de cálculo da superfície, podendo incorporar a anisotropia do sistema na análise.

Por final, foi possível fazer um cálculo detalhado de volume e área do lago, possibilitando traçar, posteriormente, no Excel, uma curva Cota $X$ Área $X$ Volume do Lago Paranoá.

\section{Resultados}

A partir da interpolação dos dados batimétricos e de perfilamento laser processados, foi interpolado os dados no FLEDERMAUS (figura 2), posteriormente, foi gerado o grid (figura 1) no SURFER 13. Com o grid gerado, foi possível calcular o volume do reservatório, conforme a tabela 1, contendo informações de área e volume em função da cota. Através desta tabela, foi feita a curva Cota x Área x Volume do Lago Paranoá (gráfico 1).

Pelos registros volumétricos anteriores, foi possível analisar a evolução do Lago Paranoá desde sua fundação (Tabela 2). O primeiro registro que se tem do Lago Paranoá é um mapa topográfico datado de antes da sua construção, em 1960. Desde o represamento do Rio Paranoá, foi possível calcular uma perda volumétrica de $6.4 \%$ do seu volume original, um total de $31.571 .377 \mathrm{~m}^{3}$, assoreando numa taxa de, aproximadamente, 563.774.58 $\mathrm{m}^{3}$ por ano. 


\begin{tabular}{rllllr}
\hline ANO & COTA & ÁREA & VOLUME & $\begin{array}{c}\text { PERDA } \\
\text { VOLUMÉ- } \\
\text { TRICA }\end{array}$ \\
\hline & $m$ & $m^{2}$ & $m^{3}$ & $\%$ & \\
1960 & 1000 & 38.881 .906 & 492.364 .111 & 0 \\
2018 & 1000 & 37.528 .552 & 460.792 .734 & 6.4 \\
\hline
\end{tabular}

Tabela 2: dados de comparação do Lago Paranoá em 1960, na sua fundação, e em 2018.

\section{Conclusões}

A integração dos dados batimétricos e de Perfilagem a Laser, para a construção da carta topo-batimétrica, mostraram-se eficazes no cálculo de volume e área do Lago Paranoá. De acordo com os resultados obtidos, é possível observar uma perda volumétrica de $6.4 \%$ do volume original do Lago, equivalendo a uma taxa de assoreamento de cerca de $563.774 .58 \mathrm{~m}^{3}$ por ano. Os dados são coerentes, portanto, o método descrito é uma ferramenta útil para o mapeamento e manejo de reservatório.

Recomenda-se que sejam realizados levantamentos periódicos para refinar a estimativa da taxa de sedimentação, de modo que seja possível realizar um monitoramento minucioso do volume útil do reservatório e aporte de sedimento.

\section{Agradecimentos}

A parceria entre a Universidade de Brasília e a ADASA que financiou a execução desse projeto. Ao Laboratório de Geofísica Aplicada (LGA/IG/UnB) pela disponibilização dos equipamentos geofísicos, e ao professor Marco, pela orientação e apoio para o desenvolvimento do projeto.

\section{Referências}

Hosseini, M., \& Ashraf, M. A. (2015). Application of Hydrological Models Related to Land Use Land Cover Change. In: Application of the SWAT Model for Water Components Separation in Iran. Springer Hydrogeology, pp. 1:32, https://doi.org/10.1007/978-4-431-55564-3

Rowan, J. S., Goodwill, P., \& Greco, M. (1995). Temporal variability in catchment sediment yield determined from repeated bathymetric surveys: Abbeystead Reservoir, U.K. Physics and Chemistry of the Earth, 20(2), 199-206. https://doi.org/10.1016/0079-1946(95)00024-0

Walling, D. E. (1999). Linking land use, erosion and sediment yields in river basins. Hydrobiologia, 410, 223240. https://doi.org/10.1023/A:1003825813091

Dias, L. T. (2011). Modelagem do uso e ocupação do solo na bacia hidrográfica do Lago Paranoá - DF: 1998-2020. 